\title{
Trypanosoma cruzi Defined Antigens in the Serological Evaluation of an Outbreak of Acute Chagas Disease in Brazil (Catolé do Rocha, Paraíba)
}

\author{
Eufrosina S Umezawa, Maria Aparecida Shikanai-Yasuda*, Arthur Gruber**, \\ Vera L Pereira-Chioccola***, Bianca Zingales**
}

\begin{abstract}
Instituto de Medicina Tropical, Universidade de São Paulo, Av. Dr. Enéas de Carvalho Aguiar 470, 05403-000
São Paulo, SP, Brasil *Departamento de Doenças Infecciosas e Parasitárias, Faculdade de Medicina,

Universidade de São Paulo, São Paulo, Brasil **Departamento de Bioquímica, Instituto de Química,

Universidade de São Paulo, São Paulo, Brasil ***Instituto Dante Pazzanese de Cardiologia, São Paulo, Brasil
\end{abstract}

Immunoglobulin $G$ and $M$ humoral response to recombinant protein B13 and glycoconjugate LPPG Trypanosoma cruzi defined antigens was evaluated by ELISA in 18 patients in the acute phase of Chagas disease, who were contaminated on the same occasion. LPPG showed $100 \%$ positivity detecting both IgM and IgG antibodies, while positivity of 55-65\% was observed for B13. An epimastigote alkaline extract (EPI) also showed high sensitivity for acute IgM (100\%) and IgG (90\%) antibodies. However LPPG had better discriminatory reactivity since with EPI two patients showed negative IgG and several other sera presented $O D$ values for IgG and IgM antibodies very close to the cutoff. Thus, it is suggested that detection of IgM antibodies by LPPG may be used for diagnosis of the acute phase of Chagas disease. An intense decline of IgG and IgM antibodies to the three antigens was observed in response to anti-T. cruzi chemotherapy in all acute phase patients. After treatment, six (30\%) individuals maintained IgG positivity to EPI, LPPG, and B13 with lower reactivity than that measured at the acute phase. For comparison, serology of a group of 22 patients in the chronic phase of Chagas disease and also submitted to chemotherapy was determined. Positive IgM antibodies to EPI, LPPG and B13 were detected in only 5-9\% cases. In all chronic-phase patients IgG antibodies highly reactive to the three antigens were present and no significant decrease resulted after benznidazole administration. These observations reinforce previous reports that treatment in the acute phase may reduce or eliminate the parasite.

Key words: Chagas disease - acute phase - serology -LPPG - B13 recombinant protein - Trypanosoma cruzi

Chagas disease, caused by Trypanosoma cruzi, is a widespread illness in Latin America where 16-18 million people (Moncayo 1993) are affected. The most important $T$. cruzi transmission mechanism to humans is throughout infected triatomines' feces. The second most important route is blood transfusion. Human migration from endemic areas to urban centers is providing a rising risk of transfusional Chagas disease in all Latin America and in non-endemic countries. Congenital transmission occurs most frequently by colonization of placenta by the parasite. The incidence of congenital transmission varies according to different circumstances and geographical situations. At present, this problem is deserving the attention of

This investigation was supported by grants from FAPESP, CNPq, Fundação Nacional da Saúde, LIM49-FMUSP and UNDP/World Bank/WHO Special Programme for Research and Training in Tropical Diseases

Received 4 April

Accepted 22 June 1995 governmental health programs in few Latin America countries. Less important mechanisms of transmission are accidental laboratory contamination and organ transplantation from infective donors. In this case, the problem is exacerbated by the immunosuppressive therapy generally administered to the organ recipient.

In Brazil at least three reports suggest $T$. cruzi transmission by oral route. The first describes an epidemic outbreak in Teutônia with 17 persons infected simultaneously, probably due to the ingestion of contaminated meal with urine from infected marsupials (Dias 1979). Another outbreak was observed in the State of Pará where 4 persons seem to have been infected through the ingestion of food contaminated with triatomine excreta (Dias 1979). A third outbreak was reported in the State of Paraíba in the municipality of Catolé do Rocha in October 1986, when 26 individuals acquired acute Chagas disease most probably by drinking sugar-cane juice contaminated with feces of triatomines or marsupial secretion (ShikanaiYasuda et al. 1991). 
Acute phase in Chagas disease is characterized by patent parasitemia which is followed by a life-long chronic phase with subpatent parasitemia (Brener \& Camargo 1982). The small number of detected human acute cases and the short duration of this phase are obstacles for accurate clinical investigations at this stage of the disease. It has been shown that specific chemotherapy applied in the acute phase, leads in many cases to successful cure (Rassi \& Luquetti 1992).

Diagnosis of acute phase is mainly accomplished by detection of the parasite either by direct blood examination or indirectly by xenodiagnosis, hemoculture and inoculation in experimental animals. Most of theses tests are time-consuming, show low and variable sensitivity and can only be done in specialized centers.

Antibodies, both IgG and IgM, can be detected in serum usually following the first clinical manifestation of the acute phase of $T$. cruzi infection. In the succeeding chronic phase, $\operatorname{IgG}$ antibodies are to be regularly found in serum (Camargo \& Amato Neto 1974, Schmuñis et al.1978, Matsumoto et al.1993).

The antigens commonly used in serodiagnosis of Chagas disease are fixed epimastigote forms or a complex mixture of proteins and glycoconjugates extracted from whole parasites (Camargo 1992). In the last years, efforts have been made for development of new diagnostic tests employing purified antigens, recombinant proteins or synthetic peptides in order to make a more reproducible and specific diagnosis of Chagas disease (Franco da Silveira 1992).

In this study we present the evaluation of IgM antibodies significance for the serological diagnosis of the acute phase of Chagas disease. We investigated the $\operatorname{IgM}$ and $\operatorname{IgG}$ appearance in a group of individuals contaminated with $T$. cruzi in a festive reunion in Catolé do Rocha and those who developed the acute phase. All individuals were submitted to specific treatment with benznidazole, as described in the original report which also presents the clinical characteristics of these patients (Shikanai-Yasuda et al. 1991). This group shows extremely interesting and unique features since it constitutes a homogeneous sample in reference to the date and route of contamination (possibly with the same strain(s) of $T$. cruzi); chronology of appearance of the acute phase and application of the same chemotherapeutic protocol. For the serological evaluation we used an alkaline epimastigote extract (Lissaldo et al. 1994) and two purified antigens: a recombinant protein, denominated B13 (Gruber \& Zingales 1993) and a T. cruzi glycoconjugate LPPG (lipopeptidophosphoglycan) (Lederkremer et al. 1990, Zingales et al. 1993). Data are compared with serology in a group of chronic chagasic patients before and after chemotherapy.

\section{MATERIALS AND METHODS}

Human sera - Group I: human sera were obtained from 18 individuals who acquired Chagas disease on the same occasion in Catole do Rocha (Paraíba, Brazil) (Shikanai-Yasuda et al. 1991). Details of these patients are shown in Table I. All individuals received benznidazole in a $7 \mathrm{mg} / \mathrm{kg} /$ day schedule for children and $5 \mathrm{mg} / \mathrm{kg} /$ day for adults during 60 days (Shikanai-Yasuda et al. 1991). After chemotherapy, all patients showed negative xenodiagnosis as determined by a single application test. Sera were collected on the 54th day after contamination and three years after the end of chemotherapy. Two additional individuals (one male and one female) who acquired Chagas disease by accidental laboratory contamination were also submitted to chemotherapy and included in the analysis. Group II: human sera were obtained from 22 patients in the chronic phase of Chagas disease from Instituto Dante Pazzanese de Cardiologia (São Paulo). The patients (15 males and 7 females), originary from different regions of Brazil, but presently living in non-endemic areas, presented positive serology for Chagas disease and $50 \%$ of them had positive xenodiagnosis. Sera were collected before treatment with benznidazole (same protocol as above) and 2-7 years afterwards (Pereira et al. 1989). All patients had negative xenodiagnosis after this period. Group III: the control group included 20 sera from the blood bank of Hospital das Clínicas (São Paulo) with negative serological reactions to Chagas disease. Sera were inactivated at $56^{\circ} \mathrm{C}$ for $30 \mathrm{~min}$ and stored in $50 \%$ glycerol at $-20^{\circ} \mathrm{C}$.

Antigens- Epimastigote forms of T. cruzi (Y strain) grown in liver infusion tryptose (LIT) medium were lysed with $0.3 \mathrm{~N} \mathrm{NaOH}$ overnight at $4^{\circ} \mathrm{C}$ with stirring. After neutralization $(\mathrm{pH} 7.2)$ with $0.3 \mathrm{~N} \mathrm{HCl}, 2 \mathrm{mM}$ phenylmethylsulfonylfluoride was added and the homogenate was centrifuged at 12,000 $\mathrm{g}$ for $1 \mathrm{~min}$. The supernatant, denominated EPI (Lissaldo et al. 1994), was stored at $-70^{\circ} \mathrm{C}$. The recombinant $\mathrm{B} 13$ T. cruzi protein fused to $\beta$-galactosidase was obtained and purified as previously described (Gruber \& Zingales 1993). Lipopeptidophosphoglycan (LPPG) was purified from epimastigote forms by the butanol method (Lederkremer et al. 1990). Protein was measured by a Lowry modified method (Hartree 1972). Neutral sugars were determined by the phenol-sulfuric acid method (Dubois et al. 1956).

Enzyme-linked immunosorbent assay (ELISA) - Plates (Nunc, PolySorp, Roskilde, Denmark) 
TABLE I

Individual characteristics and acute phase clinical and laboratorial data of patients $(\mathrm{n}=18)$ from Catolé do Rocha

\begin{tabular}{|c|c|c|c|c|c|c|c|c|c|c|c|c|c|}
\hline \multirow[t]{2}{*}{ No. } & \multirow[t]{2}{*}{$\begin{array}{c}\text { Sex } \\
(\mathrm{M} / \mathrm{F})\end{array}$} & \multirow[t]{2}{*}{$\begin{array}{c}\text { Age } \\
\text { (years) }\end{array}$} & \multirow{2}{*}{$\begin{array}{c}\text { Incubation } \\
\text { period } \\
\text { (days) }\end{array}$} & \multirow{2}{*}{$\begin{array}{l}\text { Fever } \\
\text { period } \\
\text { (days) }\end{array}$} & \multirow[t]{2}{*}{ ECG } & \multirow[t]{2}{*}{$\begin{array}{l}\text { XE } \\
( \pm)\end{array}$} & \multirow[t]{2}{*}{$\begin{array}{r}\text { CML } \\
(\%)\end{array}$} & \multicolumn{4}{|c|}{$\begin{array}{c}\text { ELISA (OD) } \\
\text { LPPG } \\
\end{array}$} & \multicolumn{2}{|c|}{ B13 } \\
\hline & & & & & & & & $\operatorname{IgM}$ & $\operatorname{IgG}$ & $\operatorname{IgM}$ & IgG & $\operatorname{IgM}$ & $\mathrm{IgG}$ \\
\hline 1 & $\mathrm{~F}$ & 44 & 9 & 32 & RBB & - & 32 & .59 & .54 & .60 & .80 & .40 & 1.16 \\
\hline 2 & $\mathrm{M}$ & 9 & 21 & 16 & $\mathrm{~N}$ & nd & 26 & .58 & .46 & 1.16 & 1.08 & .28 & .19 \\
\hline 3 & M & 47 & 16 & 28 & DVP & + & inc & .94 & .61 & 1.40 & 1.42 & .16 & .82 \\
\hline 4 & $\mathrm{M}$ & 38 & 19 & 5 & nd & $\mathrm{nd}^{*}$ & inc & .48 & .45 & .77 & 1.43 & .23 & .07 \\
\hline 5 & $\mathrm{M}$ & 53 & 14 & 16 & RBB & + & inc & .51 & 1.12 & 1.30 & 2.10 & .10 & .13 \\
\hline 6 & $\mathrm{M}$ & 25 & 14 & 15 & $\mathrm{~N}$ & + & inc & .38 & .43 & 1.16 & .94 & .08 & .38 \\
\hline 7 & M & 12 & 13 & 33 & APC & + & inc & .84 & .35 & 1.32 & .72 & .24 & .34 \\
\hline 8 & $\mathrm{~F}$ & 13 & 14 & 5 & $\mathrm{~N}$ & + & inc & .48 & .29 & 1.14 & .70 & .41 & .22 \\
\hline 9 & $\mathrm{~F}$ & 18 & 14 & 7 & $\mathrm{~N}$ & nd & inc & .78 & .63 & 1.56 & .60 & .25 & .32 \\
\hline 10 & $\mathrm{M}$ & 24 & 7 & 25 & $\mathrm{~N}$ & $-*$ & 14 & .24 & .49 & 1.01 & .60 & .15 & .23 \\
\hline 11 & $\mathrm{~F}$ & 22 & 17 & 25 & nd & + & inc & .56 & .25 & 1.00 & 1.00 & .12 & 1.00 \\
\hline 12 & M & 64 & 14 & 7 & $\mathrm{~N}$ & + & inc & .40 & .92 & 1.10 & 1.75 & .09 & .69 \\
\hline 13 & M & 46 & 13 & $>40$ & RBB & $-*$ & inc & .46 & .83 & .81 & .80 & .26 & .60 \\
\hline 14 & $\mathrm{~F}$ & 45 & 14 & $>30$ & $\mathrm{~N}$ & $+*$ & inc & .53 & .45 & .89 & 1.02 & .16 & .87 \\
\hline 15 & $\mathrm{~F}$ & 43 & 12 & 45 & $\mathrm{~N}$ & + & inc & .76 & .19 & 1.18 & .61 & .78 & .17 \\
\hline 16 & $\mathrm{~F}$ & 20 & 21 & 35 & $\mathrm{~N}$ & + & inc & .71 & .06 & 1.36 & .25 & .25 & .09 \\
\hline 17 & $\mathrm{~F}$ & 8 & 14 & 15 & $\mathrm{~N}$ & - & inc & .25 & .30 & 1.20 & .60 & .10 & .14 \\
\hline 18 & $\mathrm{~F}$ & 37 & 14 & 15 & nd & nd & inc & .35 & .26 & .85 & .40 & .26 & .28 \\
\hline Cutof & & & & & & & & .20 & .20 & .25 & .20 & .20 & .20 \\
\hline
\end{tabular}

ECG: electrocardiographic study; RBB: right bundle block; DVP: disturbance of ventricular repolarization; APC: atrial premature complexes; N: normal; XE: xenodiagnosis; $\left(^{*}\right)$ patients under specific treatment with benznidazole; CML: complement-mediated lysis. ELISA (OD): enzyme-linked immunosobent assay (optical density); nd: not determined; inc: inconclusive.

were alternatively coated with: $300 \mathrm{ng}$ protein/well of EPI; $50 \mathrm{ng}$ protein/well of B13 recombinant protein or $100 \mathrm{ng}$ hexose equivalent/well of LPPG. B13 and LPPG were dissolved in PBS, pH 7.2. EPI was solubilized in carbonate-bicarbonate buffer $0.05 \mathrm{M}, \mathrm{pH}$ 9.6. The ideal concentration of each antigen at different serum dilutions was established from saturation curves. After antigen incubation for $2 \mathrm{hr}$ at $37^{\circ} \mathrm{C}$ and for $18 \mathrm{hr}$ at $4^{\circ} \mathrm{C}$, plates were blocked with 5\% defatted milk (Nestlé) in PBS-Tween $20(0.05 \%)$ for $1 \mathrm{hr}$ at room temperature. Reactivity was measured incubating 50 $\mu 1$ of coded sera diluted in $1 \%$ defatted milk-PBSTween 20 for $1 \mathrm{hr}$ at $37^{\circ} \mathrm{C}$. Serum dilutions are specified in Results. After six washes with PBSTween 20, peroxidase-conjugated goat anti-human $\mathrm{IgG}$ or IgM (Sigma) was added at dilutions of 1:6,000 and 1:5,000, respectively, for $1 \mathrm{hr}$ at $37^{\circ} \mathrm{C}$. The substrates $0.05 \% \quad \mathrm{H}_{2} \mathrm{O}_{2}$ and o-phenylenediamine $(0.4 \mathrm{mg} / \mathrm{ml})$ were added and the reaction was allowed to develop in the dark for $30 \mathrm{~min}$ at room temperature. The reaction was stopped by the addition of $4 \mathrm{~N} \mathrm{HCl}$. The optical density (OD) was measured at $492 \mathrm{~nm}$ in a Multiskan plate reader (Titertek, Flow). In all tests non-chagasic sera (Group III) were included. Experiments were performed at least twice and on different days in duplicates for each serum dilution.

Statistical analysis - Samples recorded OD were analyzed by Statgraphics ${ }^{\text {TM }} 5.1$ (Statistical Graphic Corp. 1991) Software. The cutoff of each reaction was calculated as the mean OD of twenty non-chagasic sera plus 3SD. Comparison between tests and samples was performed analyzing all groups by multifactor analysis of variance (ANOVA), with Bonferroni test. Data are expressed as the mean OD and the significance of the difference was considered when the probability of equality was lower than 0.05 (Gardner \& Altman 1986).

Complement-mediated lysis $(C M L)$ - the assay was done as described (Umezawa et al. 1993).

\section{RESULTS}

Table I shows the individual characteristics of the 18 acute phase chagasic patients from Catolé do Rocha as well as data on the time of manifestation of acute phase symptoms and period of fever. The electrocardiographic study in 15 patients performed from the 33rd to the 55th day of illness gave normal results for 10 individuals. Fourteen individuals were submitted once to xenodiagnosis 
and ten $(71.4 \%)$ were positive. Two of the four xenodiagnosis negative patients were already under specific treatment when the test was applied (Table I). Serological evaluation of these patients was initially done by indirect immunofluorescence (IIF) tests with sera collected 54 days after contamination. IgM antibodies were negative in two individuals while $\operatorname{IgG}$ antibodies were detected in all patients (data not shown). Lytic antibodies were detected in only three patients and in very low levels. Inconclusive results were obtained for the other individuals since their sera promoted direct trypomastigote lysis in the absence of complement or in the presence of heat-inactivated complement (Table I).

Levels of IgM antibodies to B13 recombinant protein, to LPPG glycoconjugate and to an epimastigote alkaline extract (EPI) were determined by ELISA in 20 acute phase chagasic (APC) patients: 18 from Catolé do Rocha (Table I) and two individuals accidentally contaminated with the Y strain of T. cruzi. The serum dilutions used for each target antigen were previously established by cross-titration in order to give the best discriminatory results. These dilutions are: 1:200 for EPI; 1:100 for LPPG and 1:50 for B13 protein.

IgM reactivity data in Fig. and Tables I and II indicate positivity of $100 \%$ for the APC sera (Group I, $n=20$ ) with EPI and LPPG and of 55\% with recombinant B13 protein. Analysis of the mean OD, based on $95 \%$ confidence intervals, was significant for the three antigens (Fig.). The highest reactivity was displayed by LPPG (Table II). Sera at 1:100 dilution gave a mean OD for EPI of $.65 \pm .20$ (data not shown).

Analysis of $\operatorname{IgG}$ reactivity in APC sera (Group $\mathrm{I}, \mathrm{n}=20$ ) is summarized in Table II. The positivity of 20 pre-therapeutic patients was $90 \%$ for EPI, $100 \%$ for LPPG and $65 \%$ for B13. In this case also, reactivity to LPPG was the highest. Analysis of variance was significant between LPPG and EPI or LPPG and B13 (data not shown).

IgM reactivity was assessed three years after chemotherapy of Group I patients and results are shown in Fig. where individual serum samples are linked by transversal lines. Data for the two accidentally contaminated patients are indicated with asterisks. A clear decline of IgM antibodies was observed in all patients, but positivity in low titers was observed in $20 \%$ of the individuals for EPI and $30 \%$ for LPPG (Table II).

IgG analysis of Group I-treated patients (Table II) showed a positivity of $45 \%$ to EPI $(.36 \pm .13)$

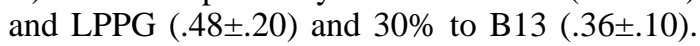
Six patients (No. 1, 3, 7, 9, 12, 14 in Table I) remained positive to the three antigens.

For comparison, a group of 22 chronic phase

\section{TABLE II}

Reactivity of $\operatorname{IgM}$ and $\mathrm{IgG}$ antibodies from sera of acute (Group I, n=20) and chronic (Group II, n=22) chagasic patients and control individuals (Group III, $\mathrm{n}=20$ ) to EPI, LPPG and B13 antigens before and after chemotherapy

\begin{tabular}{|c|c|c|c|c|c|c|}
\hline \multirow[t]{2}{*}{ Antibodies } & \multicolumn{2}{|c|}{ EPI } & \multicolumn{2}{|c|}{ LPPG } & \multicolumn{2}{|l|}{ B13 } \\
\hline & $\mathrm{M} \pm \mathrm{sd}$ & $\%$ & $\mathrm{M} \pm \mathrm{sd}$ & $\%$ & $\mathrm{M} \pm \mathrm{sd}$ & $\%$ \\
\hline \multicolumn{7}{|l|}{ Group I- IgM } \\
\hline & $.55 \pm .20$ & 100 & $1.12 \pm .25$ & 100 & $.24 \pm .20$ & 55 \\
\hline & $.14 \pm .09$ & 20 & .31 & 30 & $.05 \pm .03$ & 0 \\
\hline \multicolumn{7}{|l|}{ Group I- IgG } \\
\hline & $.49 \pm$ & 90 & $.95 \pm$ & 100 & $.41 \pm .36$ & 65 \\
\hline alt & $.23 \pm .15$ & 45 & $.28 \pm .23$ & 45 & $.19 \pm .13$ & 30 \\
\hline \multicolumn{7}{|l|}{ Group II- IgM } \\
\hline & $.16 \pm$ & 5 & & 9 & $.14 \pm .11$ & 9 \\
\hline & $.22 \pm$ & 27 & $.13 \pm .12$ & 23 & $.20 \pm .10$ & 15 \\
\hline \multicolumn{7}{|l|}{ Group II- IgG } \\
\hline & 1.23 & 0 & & 100 & 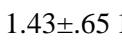 & \\
\hline after & 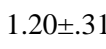 & 00 & $1.18 \pm .28$ & 100 & 1 & 100 \\
\hline 18 & & 0 & 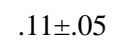 & 0 & $.10 \pm$ & \\
\hline IgG & $.05 \pm .05$ & 0 & $.09 \pm .04$ & 5 & $.09 \pm .04$ & \\
\hline
\end{tabular}

Data were obtained by ELISA and expressed as the mean of $\mathrm{OD} \pm$ standard deviation $(\mathrm{M} \pm \mathrm{sd})$. The percentage (\%) indicates positive individuals. Serum dilutions: 1:200 for EPI, 1:100 for LPPG and 1:50 for B13

chagasic (CPC) patients from Instituto Dante Pazzanese de Cardiologia (São Paulo) was analyzed before and after specific chemotherapy (Group II). Serological data are summarized in Table II. IgM positivity for the three antigens was detected in 5-9\% pre-therapeutic individuals and $100 \%$ of IgG antibodies was observed in samples collected before and after chemotherapy, with high reactivity to the three antigens. It was verified that CPC patients submitted to chemotherapy present IgG mean $\mathrm{OD}$ values approximately three times higher than those displayed by the six patients of Group I who maintained positive serology after chemotherapy. The confidence intervals showed no statistical difference between pre- and postherapy $\operatorname{IgG}$ reactivity to the three antigens (data not shown).

\section{DISCUSSION}

An intense and early humoral response against LPPG of both IgM and IgG antibodies is observed in all acute phase patients from Catolé do Rocha, as well as in the two individuals who acquired Chagas disease by accidental laboratory contamination. The high antigenicity of LPPG can be ascribed to the parasite membrane location of this glycoconjugate and to the presence of galactofuranose in this molecule (Lederkremer et al. 1980, Golgher et al. 1993). In fact, galactose in the furanoic configuration is a rare carbohy- 

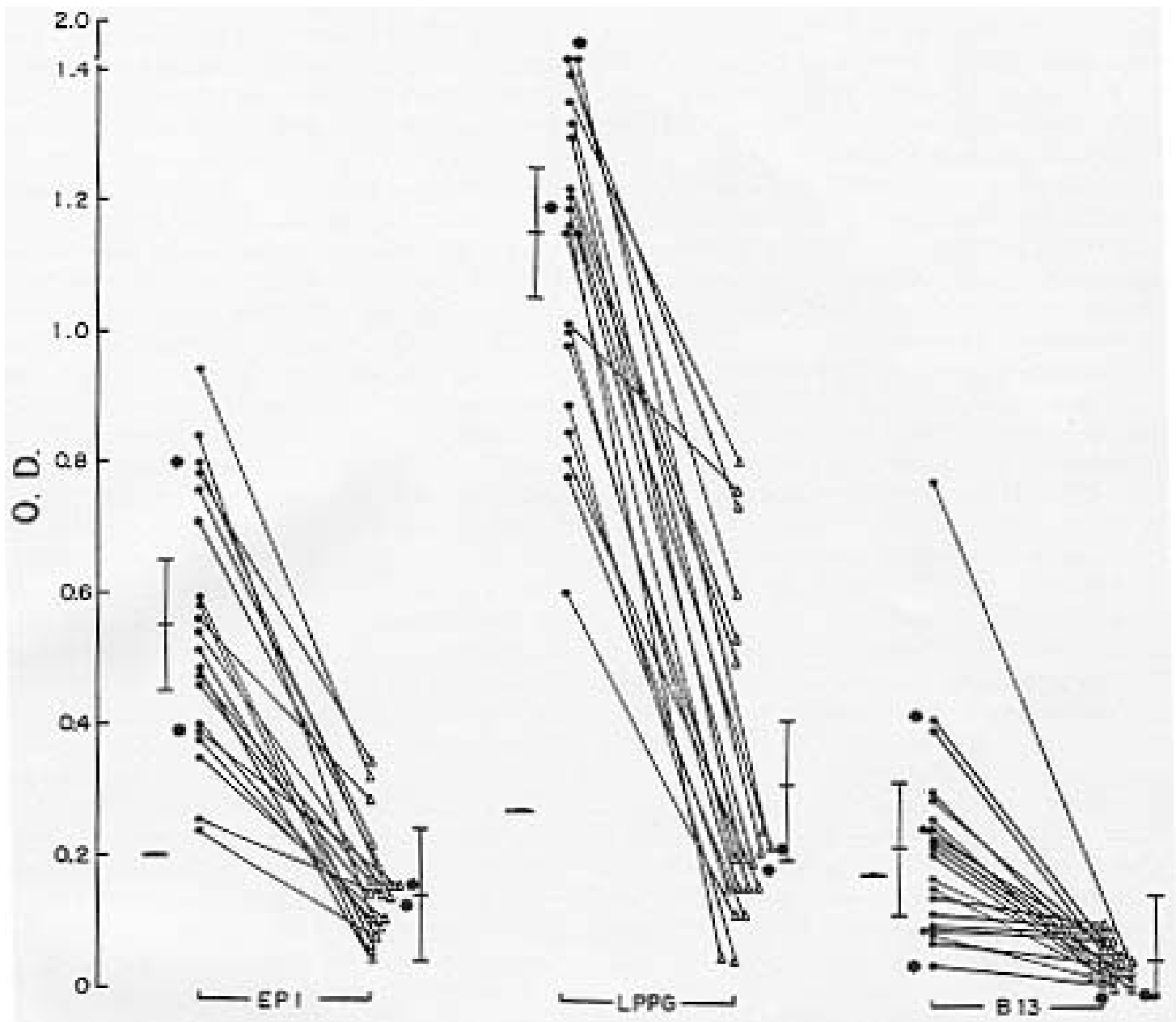

Distribution of IgM antibodies in sera of 20 patients with acute Trypanosoma cruzi infection (Group I) by ELISA. Serum dilutions: 1:200 for EPI; 1:100 for LPPG and 1:50 for B13 antigens. Asterisks indicate the two patients with accidental laboratory contamination. OD values were registered in acute phase $(\bullet)$ and three years after treatment $(\Delta)$. Arrows indicate the cutoff values. Bars show the 95\% confidence intervals for factor means (Bonferroni test).

drate in nature, not represented in glycoconjugates from vertebrates (Colli 1992). Previous reports showed IgG antibodies to galactofuranose in sera of chronic chagasic patients (Schnaidman et al. 1986, Golgher et al. 1993, Zingales et al. 1993). Data presented in this study suggest that screening of $\operatorname{IgM}$ antibodies directed to the galactofuranose-containing LPPG could be of use to diagnose Chagas acute phase. For definitive conclusion, a more representative sample of acute sera has to be analyzed. If the above observation is confirmed, then measurement of IgM antibodies to LPPG could be applied for diagnosis of acute phase in conjunction or substitution of parasitological detection, obtained by procedures which last 30-60 days. As a clear advantage, the early diagnosis of acute phase would determine the immediate application of specific chemotherapy with elevated indices of cure (Rassi \& Luquetti 1992).

Comparison of acute phase antibody reactivity to EPI and LPPG (Tables I, II) indicates that the alkaline extract of epimastigotes is also a good target antigen for both IgM and IgG. However, analysis of data in Fig. shows that IgM antibodies from some sera gave OD values for ELISA with EPI close to the cutoff value. In contrast, for LPPG the sera with lowest reactivity have OD values at least two times the value of the cutoff for this antigen. This indicates that LPPG has a better discriminatory reactivity for IgM than EPI. As an additional advantage of LPPG over EPI, the use of a purified antigen would allow more reproducible results in serological assays. Furthermore, LPPG can be easily and reproducibly purified with high yield from epimastigote forms of several strains of T. cruzi (Golgher et al. 1993).

A great individual variation in the $\operatorname{IgM}$ and 
IgG reactivity to LPPG (and EPI) was observed in acute phase patients from Catolé do Rocha (Table I, Fig.). Such behavior does not correlate with the sex or age of the patient or with clinical data (Table I). Assuming that most probably the 18 individuals of this group were infected by the same $T$. cruzi strain(s), the results favor the hypothesis that differences in antibody reactivity are dependent on host genetic factors. Alternatively, it could be conceived that patients were contaminated with different doses of parasites.

Recombinant protein B13 shows high specificity and sensitivity for IgG antibodies in chronic chagasic patients (Table II), confirming previous observations (Gruber \& Zingales 1993, Zingales et al. 1993). Data in the present study indicate that B13 protein should not be used for acute-phase serologic diagnosis since a sensitivity of only 55$65 \%$ for both IgM and IgG antibodies was observed (Table II).

All patients of Group I submitted to chemotherapy show an intense decline of $\operatorname{IgM}$ and $\operatorname{IgG}$ antibodies to the target antigens when assayed three years after treatment (Table II). A natural disappearance of $\operatorname{IgM}$ reactivity to total epimastigotes has been observed when most chagasic patients enter the chronic phase (Primavera et al. 1990). In the present study it is observed that $30 \%(6 / 20)$ of the ACP individuals show persistent IgG reactivity to EPI, LPPG and B13 after chemotherapy. However this reactivity is lower than that measured before treatment (Table II) or when compared with data of CPC patients of Group II (Table II). Analysis of individual parameters of these six ACP patients indicates no common characteristic of sex, age or particular serological reactivity in the acute phase (Table I). The only interesting feature is that three of these patients had electrocardiographic alterations in the acute phase (Table I).

The decline in IgG antibodies to the three antigens observed in the majority of Group I patients three years after benznidazole administration, in contrast to what is observed in the chronic Group II, could be indicative of the efficacy of treatment reducing or eliminating the parasite in ACP groups. This could favor previous suggestions that chemotherapy applied at early stages of infection can be successful (Rassi \& Luquetti 1992). It should be emphasized that we do not intend to propose that reduction of specific antibodies should be taken per se as criterion of cure or drug efficacy. Definitive conclusions can only be achieved by direct and sensitive parasitological diagnosis by the use of specific T. cruzi DNA probes, as shown (Wincker et al. 1994).

It has been reported that a specific class of an- tibodies ("lytic antibodies") that lyse trypomastigotes by a complement-mediated reaction (CML) show a progressive decrease in chagasic patients submitted to successful therapy (Krettli et al. 1982, Galvão et al. 1993). As a consequence it has been proposed that negativation of lytic antibodies could be considered a criterion of cure. In the present study, CML reaction was performed in sera from Group I patients before and after chemotherapy. Table I shows that only three ACP patients from Catolé do Rocha have lytic antibodies which promote very low percentage of parasite lysis. In the remaining sera direct lysis of trypomastigotes in the absence of complement was observed. These results are coincident with previous report indicating that antibodies from acute chagasic patients lyse parasite blood forms independently from the classic or alternative complement pathways (Gazzinelli et al. 1990). Measurement of lytic antibodies in Group I patients three years after chemotherapy gave inconclusive results since a large variation in the percentage of trypomastigote lysis was observed in the patients' sera and even in the same serum sample when the reaction was performed on different days (data not shown). Similar observations were reported by one of us for chronic chagasic patients (Pereira et al. 1989). Therefore, in our hands, lytic antibodies could not be used in assessing treatment efficacy in chagasic patients from Catolé do Rocha. This reinforces the need of sensitive and direct parasitological diagnosis with DNA probes.

\section{ACKNOWLEDGEMENTS}

To Professor Mário Camargo for encouragement and for critically reading the manuscript. To AR Ferreira for drawing assistance and MS Nascimento for technical help.

\section{REFERENCES}

Brener Z, Camargo EP 1982. Perspectives of vaccination in Chagas disease. Pont Acad Sci Scripta Varia 47: 145-168.

Camargo ME 1992. An appraisal of Chagas disease serodiagnosis, p. 165-178. In S Wendel, Z Brener, ME Camargo, A Rassi, (eds). Chagas disease (American Trypanosomiasis): its impact on transfusion and clinical medicine. ISBT (International Society of Blood Transfusion), São Paulo.

Camargo ME, Amato Neto V 1974. Anti-Trypanosoma cruzi IgM antibodies as serological evidence of recent infection. Rev Inst Med Trop São Paulo 16: 200-202.

Colli W 1992. Trypanosoma cruzi: molecular aspects of the host-parasite interaction, p. 259-275. In JE Allende Simposio RELAB (Red Latinoamericana de Ciencias Biologicas) \#2, Santiago.

Dias JCP 1979. Mecanismos de transmissão, p. 152 174. In Z Brener, Z Andrade, (eds). Trypanosoma cruzi e Doença de Chagas. Guanabara Koogan, Rio 
de Janeiro.

Dubois M, Gilles KA, Hamilton JK, Rebers PA, Smith F 1956. Colorimetric method for determination of sugars and related substances. Anal Chem 28: 350356.

Franco da Silveira J 1992. Trypanosoma cruzi recombinant antigens for serodiagnosis, p. 207-218 In S Wendel, Z Brener, ME Camargo, A Rassi, (eds). Chagas disease (American Trypanosomiasis): its impact on transfusion and clinical medicine. ISBT (International Society of Blood Transfusion), São Paulo.

Galvão LMC, Nunes RMB, Cançado JR, Brener B, Krettli AU 1993. Use of lytic antibodies in assessing cure after treatment of Chagas disease: a 10 year follow-up study. Trans $R$ Soc Trop Med Hyg 87: 220-223.

Gardner MJ, Altman D 1986. Confidence intervals rather than P values: estimation rather than hypothesis testing. Brit Med J 292: 746-750.

Gazzinelli RT, Pereira MES, Romanha A, Gazzinelli GM, Brener Z 1990. Direct lysis of Trypanosoma cruzi: a novel effector mechanism of protection mediated by human anti-gal antibodies. Parasite Immunol 13: 345-356.

Golgher DB, Colli W, Souto-Padron T, Zingales B 1993. Galactofuranose-containing glycoconjugates of epimastigote and trypomastigote forms of Trypanosoma cruzi. Mol Biochem Parasitol 60: 249-264.

Gruber A, Zingales B 1993. Trypanosoma cruzi: characterization of two recombinant antigens with potential application in the diagnosis of Chagas disease. Exp Parasitol 76: 1-12.

Hartree EF 1972. Determination of protein: a modification of the Lowry method that gives a linear photometric response. Anal Biochem 48: 422-427.

Krettli AU, Cançado JR, Brener Z 1982. Effect of specific chemotherapy on the levels of lytic antibodies in Chagas disease. Trans R Soc Trop Med Hyg 76: 334-337.

Lederkremer RM, Casal OL, Alves MJM, Colli W 1980. Evidence for the presence of D-galactofuranose in the lipopeptidophosphoglycan from Trypanosoma cruzi. FEBS Lett 116: 25-29.

Lederkremer RM, Lima C, Ramirez ML, Casal OL 1990. Structural features of the lipopeptidophosphoglycan from Trypanosoma cruzi common with the glycophosphatidylinositol anchors. Eur J Biochem 192: 337-345.

Lederekremer RM, Lima C, Ramirez MI, Ferguson MAJ, Homans SW, Thomas-Oates J 1991. Complete structure of the glycan of lipopeptidophosphoglycan from Trypanosoma cruzi epimastigotes. J Biol Chem 266: 23670-23675.

Lissaldo AM, Hoshino-Shimizu S, Umezawa ES, Stolf
AMS 1994. Alkaline soluble Trypanosoma cruzi epimastigote antigen (ASEA) applied to dot-Elisa. Rev Inst Med trop São Paulo 36: 163-166.

Matsumoto TK, Hoshino-Shimizu S, Nakamura PM, Andrade HF, Umezawa ES 1993. High resolution of Trypanosoma cruzi amastigote antigen in serodiagnosis of different clinical forms of Chagas disease. J Clin Microbiol 31: 1486-1492.

Moncayo A 1993. Chagas Disease, p. 67-75. In Tropical Disease Report Progress 1991-92. World Health Organization, Geneva.

Pereira VL, Levy AM, Boainain E 1989. Xenodiagnóstico, hemocultura e teste de lise mediada por complemento como critérios de seleção de pacientes chagásicos crônicos para quimioterapia. Rev Inst Med Trop São Paulo 31: 301-307.

Primavera KSC, Umezawa ES, Peres BA, Camargo ME, Hoshino-Shimizu S 1990. Chagas disease: IgA, IgM and IgG antibodies to $T$. cruzi amastigote, trypomastigote and epimastigote antigens in acute and in different chronic forms of the disease. Rev Inst MedTrop São Paulo 32: 172-180.

Rassi A, Luquetti AO 1992. Therapy of Chagas Disease, p. 237-247. In S Wendel, Z Brener, ME Camargo, A Rassi, (eds). Chagas disease (American Trypanosomiasis): its impact on transfusion and clinical medicine. ISBT (International Society of Blood Transfusion), São Paulo.

Schmuñis GA, Szarfman A, Coarasa L, Guilleron C, Peralta JM 1978. Anti-Trypanosoma cruzi agglutinins in acute human Chagas disease. Am J Trop Med Hyg 29: 170-178.

Schnaidman BB, Yoshida N, Gorin PAJ, Travassos LR 1986. Cross-reactive polysaccharides from Trypanosoma cruzi and fungi (specially Dactylium dendroides). J Protozool 33: 186-191.

Shikanai-Yasuda MA, Brisola Marcondes C, Guedes LA, Siqueira GS, Barone AA, Dias JCP, Amato Neto V, Tolezano JE, Peres BA, Arruda Jr ER, Lopes MH, Shiroma M, Chapadeiro E 1991. Possible oral transmission of acute Chagas disease in Brazil. Rev Inst Med Trop São Paulo 33: 351-357.

Umezawa ES, Stolf AMS, Zingales B 1993. Trypanosoma cruzi: different surface antigens of trypomastigotes are targets of lytic antibodies. Acta Trop 54: 41-53.

Wincker P, Britto C, Pereira JB, Cardoso MA, Oelemann W, Morel CM 1994. Use of simplified polymerase chain reaction procedure to detect Trypanosoma cruzi in blood samples from chronic chagasic patients in a rural endemic area. Am J Trop Med Hyg 51: 771-777.

Zingales B, Golgher D, Marmorato PG, Souto RP, Gruber A 1993. Molecular approaches to diagnosis of Chagas disease: use of defined antigens and a target ribosomal RNA sequence. Biol Res 26: 89100. 
94 Serology in an Outbreak of Acute Chagas Disease - ES Umezawa et al. 